\title{
Multiculturalismo, Estado e Modernidade - As Nuanças em Alguns Países Europeus e o Debate no Brasil
}

Livio Sansone

W ão há dúvida de que, no Brasil como em outros países, o termo para a linguagem comum. Hoje, basta folhear qualquer publicação periódica para nos depararmos com artigos, matérias e propagandas com temas étnicos, que vão desde comida até produtos de beleza. Resta a dúvida, porém, se ao uso e abuso dessa "nova" palavra corresponde uma mudança real da sociedade na forma de lidar com a diferença, ou se, de maneira paradoxal, as relações raciais mudaram relativamente pouco, embora a sociedade política e até parte da sociedade civil tenham escolhido se definir como multiétnicas. Este estudo se propõe a explorar um aspecto particular do que me parece ser a crescente distância entre a linguagem em torno da etnicidade formulada por alguns setores da sociedade e a realidade cotidiana das relações raciais

No Brasil, o debate sobre o fenômeno do multiculturalismo tem mostrado essa distância entre discurso e prática social (Fry, 2000). O objetivo deste artigo é contribuir para a contextualização de tal discurso, histórica e sociologicamente. Para tanto, descrevo como esse fenômeno surgiu enquanto ideal de sociedade em países europeus que há

DADOS - Revista de Ciências Sociais, Rio de Janeiro, Vol. 46, nº3, 2003, pp. 535 a 556. 


\section{Livio Sansone}

muito estão tentando lidar com a diferença étnica, racial e cultural, a partir de um conjunto de ações públicas. Após enfocar a situação desses países, teço considerações sobre o multiculturalismo no Brasil. Saliento a importância de analisar tanto o debate como o olhar "de fora", evitando, porém, reduzir a reflexão comparativa unicamente ao eixo Estados Unidos-Brasil. Em tempo, preciso fazer uma confissão: embora me tenha tornado um pessimista com relação ao poder supostamente libertador das identidades setoriais, como aquelas de cunho étnico, já que não considero que elas sejam em si emancipadoras, estou convencido de que é fundamental manter uma postura otimista a respeito do multiculturalismo. Isto porque a correção das desigualdades raciais no Brasil não pode ser esperada a partir da operação da "mão invisível do mercado". Na verdade, são absolutamente necessárias tanto medidas compensatórias da desigualdade social quanto ações reparatórias do racismo histórico, assim como intervenções multiculturalistas - no sentido de se criarem melhores condições para a aceitação dos diferentes e para uma educação anti-racista.

Vou me ater aos países europeus que receberam uma forte imigração, sobretudo a partir do segundo pós-guerra, as assim chamadas sociedades multiculturais, onde se verifica uma relação orgânica entre discurso, lei e práticas multiculturais ${ }^{1}$. Refiro-me concretamente à Alemanha, França, Bélgica, Holanda e Inglaterra ${ }^{2}$, em cuja base do multiculturalismo se encontram três fontes clássicas.

Em primeiro lugar, há o pacto social - o compromisso do Estado e de parte das elites de cuidar dos excluídos e pobres. Nesse sentido, pensa-se os pobres - as categorias de excluídos - como passíveis de medidas legislativas particulares, como a redistribuição de renda, por exemplo. Claro que se trata de um processo de incorporação seletiva de uma parte deles: nem todos podem e devem ser ajudados, somente aqueles que se submetem às regras do convívio estabelecidas pelo pacto social. Na Holanda, o primeiro seguro-desemprego foi instaurado em 1522 e logo foi preciso definir quem era digno de recebê-lo (Swaan, 1988; Regt, 1978) ${ }^{3}$. Para isso, estabeleceram-se direitos especiais, mesmo no contexto de uma legislação universalista. O objetivo substancial era, e ainda é, prevenir ou, pelo menos, administrar o conflito.

A segunda fonte importante é o passado colonial, quer dizer, a forma pela qual se procederam nas colônias a organização e, às vezes, até a 
militarização do confronto em face da diversidade cultural. Nesse sentido, pode-se falar de diferentes estilos de colonialismo: a) o sistema britânico do indirect rule ou governo indireto; b) o sistema das sociedades plurais como, por exemplo, a do Império Holandês, que se baseava na existência de um direito étnico. Assim, no Suriname, até os anos 30, o direito civil e, em alguns casos, o penal variavam de acordo com o grupo étnico. Existia o direito de propriedade para os javaneses, diferente daquele aplicado aos hindustanos, que, por sua vez, diferia da forma jurídica (ocidental) pela qual eram julgados os negros e mestiços. Um sistema não muito diferente valia na África do Sul sob o regime do apartheid - não por acaso, uma palavra holandesa; e c) no extremo oposto, havia a versão do colonialismo do Império Francês, baseada na noção de francité, de universalismo na "boca do fuzil", e na atratividade de uma ocidentalização possível, embora a altos custos (ou a duras penas), para uma parcela da população "nativa" (Diouf, 1999). Com efeito, práticas e teorias divergiam em muitos casos, e todo colonialismo, pelo menos na África, em algum momento lançou mão de ambos os tipos de domínio, o direto e o indireto.

Todos esses estilos de colonialismo previam a institucionalização de algum tipo de etnicização dos direitos e deveres, embora, depois da Segunda Guerra Mundial, muitas vezes associados a um discurso de igualdade e de respeito à diferença. De qualquer forma, os três estilos levaram a hábitos étnicos e culturais e a consensos que se mostraram tenazes e capazes de influenciar bastante a época pós-colonial. Nos últimos anos, porém, esses sistemas estão sendo colocados em discussão pelo contexto da internacionalização, que altera a relação entre colônia e metrópole a partir das grandes migrações e da globalização das culturas. Depois da Segunda Guerra Mundial e, com mais intensidade, nas últimas duas ou três décadas, é a colônia que vem para a metrópole, enquanto, ao mesmo tempo, a metrópole permanece na colônia, inclusive se enraizando ainda mais nela. Nunca se falou tanto o holandês no Suriname e o francês no Mali como hoje em dia.

A terceira fonte clássica é a tradição, que diz respeito às formas de se lidar com as diferenças étnicas e regionais internas desses países europeus (Lucassen e Penninx, 1994). Trata-se do assim dito "regionalismo" de alguns deles que se afirmam como Estados-nação na Europa a partir de um compromisso com as diferenças culturais regionalizadas, redistribuindo recursos e poder político para minorias e "colô- 
nias" internas. Refiro-me aos catalães, bascos, bretões, galeses, sardos, corsos etc.

É evidente que nem todo país da Europa é atingido da mesma forma por esses três fenômenos: pacto social, passado colonial e regionalismo. Um determinado país pode dar provas de generosidade e tolerância com relação ao pacto social, mas não ao regionalismo, e vice-versa. Há numerosas tentativas de entender essas variedades dividindo a Europa em modelos. Castles e Miller (1993), importantes sociólogos das migrações, muito presentes no debate sobre o multiculturalismo e inspirados por Dumont, tentaram classificar os cinco países europeus anteriormente mencionados, uns como mais, outros como menos, de multiculturalistas. Fundamentalmente, eles insistiram no fato de que os princípios da jus sanguinis, que estariam na base das Kulturnazion, e da jus soli, que estariam na origem da Staatnazion, ainda são os verdadeiros inspiradores das formas de lidar com as diferenças étnicas. Castles e Miller dividiram os países europeus de grande migração em três modelos: de exclusão diferencial - a Alemanha; de assimilação - a França; e de multiculturalismo - a GrãBretanha. A seguir, procuro argumentar que a situação européia é mais complexa que isso.

O Conselho da Europa, em um esforço de pragmatismo e postura ecumênica, optou por dividir de outra forma os países europeus com relação à multiculturalidade, salientando o fator variedade. De um lado, estariam países como a França, onde a nacionalidade é vista como o início da integração; de outro, países como a Alemanha, onde a nacionalidade é tida como o resultado final do processo de integração. Na Alemanha, Suíça, Bélgica e França, a ênfase seria na cidadania; já na Holanda, Suécia, Noruega e Dinamarca, no pluralismo cultural. A Inglaterra é um caso à parte, pois o realce não é no pluralismo cultural, mas na luta contra o racismo. Nesse sentido, a Inglaterra é o único país europeu onde as agências governamentais utilizam o termo relações raciais, em lugar de relações interétnicas.

De qualquer forma, em todos esses países, a diversidade étnica, resultado da imigração, colocou em discussão o pacto social. Uma coisa seria aceitar pagar impostos para subsidiar os desempregados e os pobres nativos; outra seria fazê-lo para beneficiar aqueles que, como os claimants, na Inglaterra, têm direito à seguridade social mesmo sendo paquistaneses que nem ao menos falam inglês corretamente, ou mu- 
çulmanos, que lidam de forma "diferente" com as tradições culturais britânicas. A imigração em massa também coloca em discussão o equilíbrio interno de um país tanto em relação às suas minorias regionais - por exemplo, alterando delicados equilíbrios demográficos e eleitorais entre flamengos e valões na Bélgica - como em relação às imagens desses "outros" ("não brancos") construídas ao longo da experiência colonial - os que antes eram os sujeitos coloniais, os selvagens, incivilizados, agora moram e até trabalham conosco. Nesse sentido, a imigração tem tido um efeito quase revolucionário sobre a realidade social dos países em questão. Diversas variáveis contribuem para estabelecer diferenças na aplicação concreta de medidas multiculturalistas: primeiro, há a diferença entre discursos e práticas; segundo, a imigração manifesta-se em épocas e dimensões diferentes; terceiro, os efeitos reais dessas medidas são diferenciados.

É importante lembrar que o tema da diversidade étnica e cultural relacionado aos imigrantes se explicita em épocas distintas nos diferentes países analisados. Depois da Segunda Guerra Mundial, a Inglaterra foi a primeira a receber uma imigração maciça, já a partir dos anos 40 e 50. Ali, já no final dos anos 60, chega à idade adulta a "segunda geração" de descendentes de imigrantes do pós-guerra - os filhos dos trabalhadores contratados no Caribe anglófono. Na Holanda, somente no final dos 70 o governo reconhece, pela primeira vez, que o país é de imigração. Na França, isso se dá na década de 80, com Mitterrand. Na Alemanha, no final dos anos 90, finalmente, a legislação é alterada para permitir a dupla nacionalidade e, sendo assim os imigrantes e seus descendentes não mais seriam chamados de Gastarbeiter (trabalhador hóspede).

Embora, segundo Dumont, cada grande Estado europeu disponha de uma noção própria de cultura - na maioria das vezes arcaica -, assiste-se, nos últimos vinte anos, a uma convergência entre eles no que diz respeito às políticas de imigração e às formas oficializadas de lidar com a diferença étnica. Isso vale, inclusive, para os países do sul da Europa, que nestes tempos se transformaram de países de forte emigração em países com uma crescente e específica imigração. Aliás, a experiência dos países que somente agora estão vivendo o impacto da diversidade cultural imigrada coloca em discussão as grandes teorias que fazem da imigração parte constituinte da modernidade, esquecendo que a globalização está colocando em movimento regiões inteiras, não apenas na direção dos países mais desenvolvidos, mas 


\section{Livio Sansone}

também daqueles cujas fronteiras ou economia informal permitem alguma inserção, mesmo que precária. De fato, algumas das mais recentes migrações são Sul-Sul, rumo a novos centros que surgiram próximo da periferia, onde a diversidade se explicita de forma traumática, como as migrações do Sri Lanka para os Emirados Árabes ou as do Mali para a Nigéria.

Além de se tratar de países com culturas distintas, é preciso acrescentar que hoje as políticas que dizem respeito à diferença etnocultural mostram, em cada país, com relação ao passado e às três fontes clássicas mencionadas antes, tanto continuidade como descontinuidade. Um forte elemento de continuidade depende do "enraizamento" do multiculturalismo na história do Estado social e do ensino obrigatório. Se o serviço público é a esfera em que se experimentam medidas em prol de minorias, como quotas, programas de treinamento e planos de carreira, a escola pública é o palco principal do discurso pró-diversidade do multiculturalismo. Sobretudo na Holanda, na Alemanha e na Inglaterra, os respectivos Ministérios da Educação investiram muito dinheiro e recursos na implementação de medidas multiculturalistas, executando políticas afins nas escolas e estimulando os professores a formarem uma visão de mundo um pouco mais tolerante e cosmopolita do que antes (embora segundo princípios que já critiquei antes, por meio dos quais as culturas de maioria e minoria coexistem em estilo mosaico ou patchwork) ${ }^{4}$. Na maior parte dos casos, trata-se de um esforço feito com grande seriedade. Nestes cinco países, Holanda, França, Alemanha, Inglaterra e Bélgica, o Estado gerencia as medidas e articula os discursos acerca do multiculturalismo. De fato, este surge como vontade e resposta do Estado, muitas vezes até contra os interesses da iniciativa privada, que chega a boicotar medidas como a contract compliance (a obrigação, por parte das empresas contratadas pelo Estado, de efetivar programas de ação afirmativa para determinadas minorias).

Nesse sentido, hoje, a efetivação do multiculturalismo está, muitas vezes, colocada em discussão pela própria crise da máquina estatal, característica desta época nos cinco países mencionados. Embora, neles, o Estado continue muito presente nas políticas sociais e não pareça estar transformando-se em uma máquina punitiva com relação à pobreza - ao contrário do que aparenta acontecer nos Estados Unidos (Wacquant, 1998) -, seu poder de intervenção vem sendo se- 
veramente afetado pelos cortes dos gastos públicos e a privatização de serviços.

Nas últimas décadas, tem-se também percebido descontinuidades no que diz respeito à noção de nacionalidade e à ordem geopolítica na Europa, o que levou a uma alteração dos fluxos migratórios, com a intensificação destes na direção Leste-Oeste. O sentido da nacionalidade mudou assim que se foi tornando conhecida a possibilidade de opção pela dupla cidadania. Mesmo a concepção de integração tem sido sujeita a transformações, no âmbito de uma modificação na postura dos Estados. Por exemplo, nos últimos anos, o governo holandês priorizou, nesta seqüência, as seguintes palavras de ordem: assimilação, integração, direito a manter a própria cultura estrangeira e, finalmente, inburgering (literalmente, adoção das normas da sociedade holandesa) associada ao relaxamento das regras para concessão da dupla nacionalidade.

Outro motivo de descontinuidade é representado pela midiatização crescente das sociedades, que tem obrigado os países hóspedes a reverem suas políticas culturais. Por exemplo, hoje, a França possibilita transmissões radiofônicas em línguas que não a francesa. Até o governo de Mitterrand, era difícil uma rádio transmitir em línguas minoritárias, como o árabe ou o flamengo. Na verdade, se esses novos meios de comunicação oferecem novos espaços, também criam algumas contradições. Assim, a programação, geralmente semanal, produzida pelas pequenas elites étnicas, formadas por porta-vozes das diferentes minorias - como os jornalistas dos programas para imigrados das TVs estatais holandesa, australiana ou canadense - que se beneficiam das medidas inspiradas pelo multiculturalismo tornou-se completamente obsoleta. As TVs a cabo, via satélite, permitem que se assista, ao vivo, à programação, em italiano ou em turco, transmitida em tempo real da Itália ou da Turquia. Inclusive, existem programas de grupos fundamentalistas islâmicos que são proibidos na Turquia que, no sentido das minorias religiosas ou étnicas, ainda é um país de legislação bastante conservadora -, mas que podem ser vistos pelas comunidades turcas na Europa; e da Inglaterra transmite-se o único programa de TV em curdo. Essas novas possibilidades tecnológicas ajudaram, em muito, para que algumas comunidades, como a curda ou a sikh, fizessem de Berlim e de Londres, respectivamente, suas "capitais políticas" e, em certo sentido, também culturais (Appadurai, 1997). 


\section{Livio Sansone}

Com relação à diferença entre discursos e práticas, temos, entre outros, o caso da Inglaterra. Neste país o discurso multicultural é abertamente assumido pelo Estado, que tem sido pioneiro na Europa em introduzir medidas legais contra o racismo e fiscalizar sua implementação; porém, quando se trata de tomar providências concretas de apoio à religião e às línguas das minorias, há países menos abertos ao multiculturalismo do que a Inglaterra mas que, na realidade, são bem mais generosos com suas minorias, como é o caso da Bélgica - um país visto por Castles como monocultural ou, no melhor dos casos, como bicultural (francês-holandês) -, que permite às escolas islâmicas o ensino do árabe sem nenhuma restrição. Então, com relação a que somos multiculturais e de que minoria se fala?

Os resultados das medidas e práticas multiculturalistas, ademais, são diferenciados. $\mathrm{O}$ efeito dessas práticas pode ser um para os trabalhadores imigrados, outro para as minorias originárias das ex-colônias que, na maioria dos casos, estão mais familiarizadas com a língua, a religião e a cultura da metrópole - e ainda um terceiro para as minorias regionais. Assim, um país pode ser generosamente multicultural com uma minoria e pouco tolerante com outra. Por exemplo, a Itália obteve o consenso da comunidade de língua alemã no sul do Tirol, contribuindo para tornar essa província, que até os anos 60 era relativamente pobre e palco de um violento terrorismo separatista, na mais rica da Itália. Isso aconteceu por motivos geopolíticos, em conseqüência das pressões da Alemanha. A Itália não tem seguido a mesma política em relação à, mais numerosa, população da Sardenha, já que esta é politicamente menos homogênea e também menos importante no contexto geopolítico da Europa meridional.

Em geral, o ensino das línguas das minorias imigradas é mais facilitado e a liberdade religiosa mais efetiva em países como a Holanda, que têm uma tradição de divisão religiosa bem administrada para que não se transforme em cisão de cunho étnico. Isso é mais difícil de ocorrer na Inglaterra, onde ainda se vive uma relativa interconexão do Estado com a igreja anglicana, que cumpre os ideais tradicionalistas da Coroa britânica. Embora hoje a Inglaterra seja mais plural que antes, está longe de se equiparar à Holanda, onde existe, amparado pelo Estado e dentro de uma tradição de liberdade religiosa subvencionada - ou mesmo de segregação religiosa subvencionada -, um bom número de escolas hindus e islâmicas. 
Ademais, as medidas inspiradas pelo multiculturalismo podem não ter a mesma aceitação em todos os grupos para os quais elas são destinadas. Trata-se, em substância, de quatro grupos com características, às vezes, bastante diferentes: 1) os imigrantes das ex-colônias e seus descendentes, em particular originários do Caribe ou de outros lugares onde a língua e a religião da metrópole já eram enraizadas. Na maioria dos casos, trata-se de pessoas que dispõem da cidadania do país hóspede ou que têm relativa facilidade em adquiri-la; 2) os imigrantes de outros países da União Européia e seus descendentes (p. ex., os italianos na Bélgica);3) outros imigrantes e seus descendentes (p. ex., os turcos na Alemanha, Suécia e Holanda); 4) os integrantes das minorias "regionais" (p. ex., os alemães de origem russa ou romena e os irlandeses na Inglaterra). Cada um desses agrupamentos expressa demandas e se relaciona com o multiculturalismo de forma distinta. Um exemplo é o debate em torno da disciplina escolar denominada "ensino na própria língua e cultura". As comunidades afrocaribenhas na França, Grã-Bretanha e Holanda, países onde não é prevista essa disciplina, com base no fato de que as comunidades seriam, substancialmente, formadas por cidadãos negros com os mesmos direitos e línguas dos brancos nativos (Grosfoguel, 1997; Sansone, 1999), chegaram em muitos casos a se opor aos pedidos em prol desse tipo de ensino - que era promovido basicamente por grupos de imigrantes, como turcos e marroquinos - no âmbito dos conselhos escolares que reúnem docentes, alunos e pais (Vermeulen, 2001). Os afro-caribenhos tendem, pelo contrário, a pedir um ensino multirracial, menos "eurocêntrico" e declaradamente anti-racista e insistem na necessidade de enfatizar o caráter universal do ensino básico.

Alguns conflitos entre "europeus" e "estrangeiros" - por exemplo, aqueles em torno do uso do véu na escola, da necessidade pedagógica de meninos e meninas terem aula de natação juntos ou da educação sexual nas escolas - têm oposto, de fato, "ocidentalizados" (que incluem os afro-caribenhos) a "conservadores" (que, além da maioria muçulmana, incluem "nativos" de fé cristã). Em outras palavras, embora, muitas vezes, a ideologia em torno do multiculturalismo suponha uma frente única de todos os "não-brancos" ou "étnicos", no conjunto dessas minorias e no interior de cada grupo também há segmentação. Além disso, os diferentes grupos étnicos reproduzem entre si muitos dos estereótipos que a "maioria" utiliza em relação às minorias, aos quais se acrescenta toda uma série de visões etnocêntricas herdada do 


\section{Livio Sansone}

país de origem ou mesmo criada no âmbito do processo migratório. Assim, por exemplo, na Bélgica e na Holanda, italianos e turcos consideram-se, em muitos casos, "melhores trabalhadores" do que os marroquinos.

Ironicamente, outro fato também contribui para a variedade em termos de práticas e medidas inspiradas no multiculturalismo: o esvaziamento do poder do Estado, em conseqüência não somente da retração do gasto público, mas também da internacionalização de parte da legislação. Isso leva a uma crescente convergência de Estados-nação, como resultado da ação da União Européia em prol da harmonização da legislação pertinente aos direitos e deveres dos imigrados e das minorias étnicas em geral. As diferenças nacionais também diminuem em virtude da reduzida influência da autoridade centralizadora do Estado e do fortalecimento, na Europa norte-ocidental, das regiões urbanas com alcance ou até mesmo território transnacional (Randstad, Ruhrgebied, Île de France, Grande Milão etc.). Assiste-se assim a uma progressiva diferenciação entre cidades do mesmo país: entre pequenas e grandes cidades e entre cidades de tradição social-democrata e de tradição mais conservadora. Na Alemanha, a diferença entre as políticas multiculturais em duas cidades como Munique e Berlim é enorme, muito maior que entre dois países, muitas vezes tidos como intrinsecamente diferentes no que diz respeito à noção hegemônica de cultura, como a França e a Alemanha. Em um mundo que se globaliza e universaliza em termos de direitos e leis, às vezes as práticas cidadãs são muito mais diversificadas do que se acredita. Inclusive, as cidades competem entre si por recursos e pela instalação de novas empresas. Nesse processo, uma cidade pode atrair ou não as minorias étnicas mais pobres e menos qualificadas do ponto de vista profissional. Ademais, já se consolidaram redes importantes que levam um grupo particular a se concentrar em uma determinada cidade. Na Holanda, Roterdã atrai os turcos; Amsterdã, os surinameses de origem creole; e Haia, os surinameses de origem hindustana.

Finalizando esse tema, hoje, a integração dos "estrangeiros" nesses países se dá em um contexto mais fluido do que no passado, definido por cidades e regiões mais do que por Estados, e caracterizado tanto pela hetero quanto pela homogeneização cultural.

O último problema sobre o qual vou discorrer é particularmente alarmante: as categorias necessárias para a implementação de políticas 
multiculturais tendem a ser construções rígidas e estanques que obliteram as diferenças de classe no interior de uma determinada minoria étnica, escondem o que de comum essa minoria pode ter com outras minorias ou com algumas camadas sociais da maioria, fossilizam dinâmicas culturais internas a um grupo, fortalecendo divisões históricas (os árabes versus os berberes; os turcos versus os curdos), coletivizam indivíduos, transformando-os em "grupos étnicos", e tendem a ser etnogenéticas - elas "fazem" o grupo étnico e criam sua "problemática". Isso porque, em um pacto que podemos chamar de faustiano, as culturas étnicas que merecem apoio são aquelas de grupos tidos como pobres ou marginalizados. Na Holanda, as agências do Estado tiraram os chineses, um grupo numericamente importante, das categorias que merecem apoio, porque estes não estariam com graves problemas sociais. Então, a liderança da comunidade chinesa, com medo de o sucesso de uma parte de seus membros obscurecer a questão do desemprego de uma outra parcela, declarou irada: "mas nós também temos graves problemas".

É irônico que todo esse processo - em que os imigrados e seus descendentes são sempre tratados como entidades coletivas e como integrantes de uma cultura, por definição, mais "tradicional" - aconteça no âmbito de sociedades avançadas que, em muitos aspectos, estimulam o individualismo, e em trajetórias migratórias nas quais, muitas vezes, os indivíduos são também motivados pelo desejo de reconstruir uma existência em um contexto mais "moderno"que o do país de origem.

Se as categorias mencionadas são estanques tanto quanto generalizadoras, elas não dão conta da complexidade do tema. É suficiente entrar em qualquer escola de Amsterdã ou Berlim para ver meninos turcos dançando hip-hop e entender que aquilo nada tem a ver com a imagem da cultura turca fornecida pelas políticas multiculturais. A prática desses jovens é muito mais poliétnica do que se imagina, e eles se organizam com muito mais sagacidade do que essas imagens mostram. As políticas multiculturais pressupõem uma coesão de classe e uma homogeneidade social e étnica entre os grupos que são problemáticos. Por exemplo, na Holanda e na Bélgica, foi introduzido o ensino do árabe e do turco na escola pública. O corpo docente estimula (e até força) todos os alunos de nacionalidade marroquina e argelina a acompanharem as aulas de "língua e cultura" árabe, e os de nacionalidade turca, as aulas de "língua e cultura" turca. Os berberes e curdos 


\section{Livio Sansone}

são, então, transformados em "árabes" e "turcos". Trata-se, pois, de uma forma de engenharia etnossocial. Não por acaso, tal prática está sendo colocada em discussão por vários agentes.

A fase antecedente à popularização do multiculturalismo caracterizava-se pela crença na integração cultural como meio e resultado da ascensão social. Naquele estágio, as culturas, tanto a do país de origem do imigrante como a do país hóspede, eram vistas pelos policy makers como um mundo relativamente impermeável à mudança, e o conhecimento de culturas e maneiras do país hóspede, enquanto tal, era visto como algo absolutamente necessário para a ascensão social. Isso indicava que o sucesso de um grupo étnico de minoria dependia, principalmente, de seu capital cultural (ver Steinberg, 1988). Hoje, com base em muita teoria em torno do multiculturalismo, há uma nova simplificação e reificação da noção de cultura, pelas quais a manutenção da diferença e da singularidade cultural seria a condição sine qua non para a ascensão social de um grupo de minoria étnica no contexto da (pós)modernidade - como se o encontro entre culturas fosse, de fato, um conflito entre blocos, e como se, mais uma vez, a posição social dependesse da vida cultural.

Com relação à facilidade com que hoje, no debate acadêmico, se evoca a necessidade de sermos multiculturais, talvez minha opinião seja uma nota um tanto dissonante da maioria das contribuições. Em primeiro lugar, porque tenho profundas dúvidas sobre o que entendo como uma "reificação" do multiculturalismo e o culto ao reconhecimento da diferença cultural. Dependendo do contexto, a diferença cultural pode me interessar, seduzir ou até assustar. Não acho que seja possível defender a diferença cultural como se defende, por exemplo, a biodiversidade. Tenho minhas dúvidas acerca de medidas e políticas públicas que consigam esgotar a complexidade da condição de minorias étnicas - mais ainda no caso de minorias racializadas - na sociedade hoje, pelo menos no contexto europeu. Duvido que essas medidas consigam dar conta, por exemplo, da variedade e mutabilidade de um fenômeno como aquele da eclética produção cultural da segunda ou terceira geração de descendentes de imigrantes, ou do surgimento de um número crescente de estilos juvenis multiétnicos, embora marcados pela racialização da diferença (ver, entre outros, Hewitt, 1984; Wulff, 1988; Alexander, 1996; Back, 1996). Essas novas formas, que podem ser definidas como pós-étnicas, nos fazem depa- 
rar com um conjunto que mistura um novo particularismo com hibridez.

Apenas acho que o mundo é muito mais interessante, plástico e sagaz do que os "resumos do mundo" apresentados pelos teóricos do multiculturalismo: o mundo real não cabe no imaginário multiculturalista. De acordo com isso, não me seduz o discurso do reconhecimento, de politics of identity, de políticas identitárias (Taylor, 1994; ver, para uma perspectiva crítica, Pierucci, 1999), embora eu também, como muitos neomarxistas, nos anos 70, assim que começou a se manifestar com todo o vigor a crise do pensamento marxista, tenha ficado estarrecido com a etnicidade ou identidade étnica. Durante muito tempo, pensamos ser a etnicidade aquela identidade coletiva que permitia recobrar a humanidade e a subjetividade que não cabiam mais no discurso da emancipação do homem por meio da luta de classe. A identidade étnica ofereceria mais e novos espaços para a agency. Chegamos a pensar que ela fosse, como tal, de esquerda, progressista. Hoje, não acho que o reconhecimento da diferença e a identidade étnica contenham em si um discurso progressista. Nem que ela seja, em si, de "esquerda" ou de "direita" ${ }^{5}$. Por outro lado, se a identidade étnica não significa exatamente emancipação, muitas vezes tende a ser pouco tolerada pelos não-étnicos - tanto os de fora como os de dentro, que não se reconhecem na versão hegemônica dessa identidade. É por isso que políticas ou medidas compensatórias baseadas no reconhecimento étnico colocam fortemente o problema dos (muitos) indivíduos que, embora potencialmente membros do grupo em questão, não se reconhecem nas suas representações coletivas ou públicas - representações, muitas vezes, construídas em um jogo que une porta-vozes e pesquisadores, ambos preocupados em fornecer uma visão mais harmônica e homogênea da "comunidade" do que muitos indivíduos percebem (ver Handler, 1988).

Se tivermos que reificar alguma coisa, que seja a tolerância para com o outro e o anti-racismo ${ }^{6}$. Como cientistas sociais, temos um papel de responsabilidade. Podemos, de fato, contribuir para abrir ou fechar espaços de negociação e encontro entre culturas. Haveremos, como pesquisadores, que enfatizar a hibridez ou, justamente, as fronteiras étnicas? Será que a emancipação de um grupo étnico subalterno depende, de toda forma, de ele ser reconhecido enquanto tal pelas políticas da identidade? Ou será que não há (mais) uma resposta unívoca? 


\section{Livio Sansone}

Nesse sentido, é importante historicizar e tornar circunstancial o discurso do multiculturalismo, evitando fazer deste mais uma variante da globalização, como nos alertam Bourdieu e Wacquant (1998), em um artigo recente sobre a internacionalização da agenda política e de abordagens teóricas geradas no âmbito das relações raciais nos $\mathrm{EUA}^{7}$. Não se pode falar em um multiculturalismo global, porque seu sentido depende do contexto, da forma pela qual é percebido pelo sujeito, da maneira como ele é empunhado pelas instituições. Não acredito que exista um discurso universal sobre a diferença cultural, menos ainda que se possa falar de universalidade nas tentativas de colocar em prática tais discursos em contextos diferentes. Graças, sobretudo, à forma de operar das Nações Unidas e suas agências, existe hoje, como resultado de cautelosas formulações diplomáticas (World Commission on Culture and Development, 1995), um discurso universal, subscrito pela maioria dos países, sobre o valor da vida, da tolerância, dos direitos das minorias, mas não do respeito à diferença cultural.

É evidente que as contradições do discurso multiculturalista, relatadas antes, se tornam ainda mais marcantes na América Latina, onde as leis e medidas nessa direção são relativamente novas e, por enquanto, pouco efetivas, embora haja países, como a Bolívia e a Colômbia, que em suas recentes Constituições se definem como países multiétnicos e multiculturais (Sansone, 1998; no prelo). Como sempre, é muito mais fácil mudar o discurso oficial sobre a diferença do que mudar a realidade de um país. Como se pode falar com tanta facilidade de medidas multiculturalistas, por exemplo, no ensino básico, em um país como o Brasil, onde a escola pública está em colapso? Não é a primeira nem, infelizmente, será a última vez que se importam ideais e "soluções" que se descontextualizam na viagem rumo ao Brasil. Trata-se de um processo que leva, às vezes, à importação de produtos, aqui tidos como inovadores, que já saíram de linha no país de origem. Produtos que, digamos assim, chegam aqui sem manual de instrução e desprovidos de uma avaliação do "Procon" (Procuradoria de Proteção e Defesa do Consumidor) do seu país de origem. A chegada do multiculturalismo como modelo de sociedade e futuro desejável no meio acadêmico brasileiro parece-me um acontecimento científico tão anacrônico e fora de contexto como a chegada e a vulgarização, no mesmo meio, da noção de cidade pós-moderna (cacofônica, eclética, 
desregulada, polivalente), não obstante a histórica ausência de planificação urbana da América Latina.

A multiculturalidade desenvolve-se, de uma forma, quando aparece como um fenômeno relativamente endógeno, em relativa sintonia com o contexto social - sinuosamente, como a etapa mais recente de um processo antigo, parte integrante da modernidade; de outra, quando a multiculturalidade e sua ideologia, o multiculturalismo, surgem em um contexto como o latino-americano. Neste, comparativamente a outras regiões do Ocidente, as fases históricas, como diz Aníbal Quijano (1989), em lugar de seguirem umas às outras, parecem acumular-se, possuindo, ao mesmo tempo, diferentes graus de modernidade. Assim, temos universalismo, racismo, novo particularismo e nova cidadania, tudo junto. Talvez outras regiões do mundo também apresentem isso, mas quero lembrar que, no debate brasileiro sobre esses temas, as teorias que nos inspiram e os livros que citamos se referem, quase todos, a países onde tanto a modernidade como, depois, a multiculturalidade e o multiculturalismo se afirmaram mais gradualmente. Penso nos países da Europa norte-ocidental e nos Estados Unidos.

Durante toda uma época, uma pletora de países fez o impossível para reclamar sua dose de modernidade. Hoje, isso parece acontecer com o multiculturalismo e a multiculturalidade. Tudo indica que todo país, para merecer um lugar digno no panteão das nações modernas e civilizadas, tem que ter suas políticas multiculturais - mesmo sem possuir uma tradição de fricção interétnica ou de diversidade cultural politicamente organizada, esquecendo que o mundo está repleto de etnicidades potenciais e não-manifestas, de muita gente que vive, perfeita e tranqüilamente, sem ser "étnica" ou, pelo menos, sem manifestar sentimentos étnicos de forma continuada. Non-ethnic ethnics, diriam nossos colegas anglo-americanos.

É evidente que, como no caso do modernismo e da modernidade, existe uma diferença entre multiculturalismo e multiculturalidade. $\mathrm{O}$ primeiro é o ideal de nacionalidade futura; a segunda é um dado que pode existir, como em algumas camadas sociais brasileiras, sem o multiculturalismo. Pode haver práticas multiculturais sem teorias ou consciência da multiculturalidade. 


\section{Livio Sansone}

Às vezes, a multiculturalidade se dá de forma autônoma, em que não é preciso teorizar as tradições culturais e a manutenção da diversidade cultural. É quando nos deparamos com o fenômeno que alguns chamam de sincretismo - e que Fernando Ortiz e seu contemporâneo Gilberto Freyre ${ }^{8}$ chamaram de "hibridez" -, formas de multiculturalidade em áreas de tolerância e espaços liminares. Nas camadas populares brasileiras, isso não acontece nos moldes que os intelectuais querem, mas de forma muito mais cacofônica e confusa, menos apolínea. Quem sabe se possa dizer, a respeito de um certo culto ao multiculturalismo, a mesma coisa que sabemos sobre as tradições - estas se inventam ou se celebram quando já estão em crise. Talvez isso ajude a entender por que, no meio acadêmico, expressões como sincretismo, crioulização e hibridez são celebrados muito mais nos países onde esses termos parecem se referir a um futuro tanto desejável quanto longínquo, do que no contexto dos estudos das relações raciais e da cultura negra no Brasil ${ }^{9}$ (Nederveen Pieterse, 2001).

O fato de a América Latina estar saturada tanto pelo pensamento católico - em si relativamente ecumênico com relação à liturgia e ao sincretismo religioso e universalista em termos de apelo ao "povo" como por estamentos, de classes "fortes" e em conflito entre si, tem sido explicado por alguns como um obstáculo surgido para políticas identitárias centradas na etnicidade (Parsons, 1968). Na maioria dos casos, nas camadas populares brasileiras, as tensões e contradições tendem a ser "explicadas" em termos de classe, mais do que de cor/raça. Não que no cotidiano dessas camadas não se sinta o racismo, mas se notam a saliência da classe e a interpenetração da cultura operária com a cultura negra - fortíssima -, contrariamente aos Estados Unidos, onde, nas últimas décadas, o percentual de participação da população negra no mercado de trabalho é relativamente baixo. Nesse sentido, é importante salientar que não é preciso ter racismo para que se tenha etnicidade. Por isso é que temos essa situação, que, para alguns, é um anacronismo, de um país racista, sem uma identidade negra politicamente organizada e determinante em termos eleitorais.

Essa condição, de relativa subalternidade do fator étnico na consciência das pessoas, embora a hierarquização da sociedade se alimente também de "diferenças" etnorraciais, não se dá somente no Brasil ou no universo afro-latino, mas em muitos outros países. De fato, na América Latina, não se encontra o fenômeno que eu chamei de "teore- 
ma étnico" (Sansone, 1998), pelo qual a existência de uma população definida como "negra" ou de descendência africana deveria estar associada, de forma automática, à presença de uma black community, um lobby negro e, por fim, uma black constituency que vota de forma maciça em candidatos negros. Esse "teorema étnico" não se encontra na maioria dos países do Atlântico Negro e, na sua forma mais completa, somente pode ser constatado nos EUA.

A maioria dos pesquisadores da "nova etnicidade" ou de fenômenos de revivescência étnica em países diferentes salienta que etnicidade e comunidade étnica nem sempre se desenvolvem juntas. Às vezes, a etnicidade cresce justamente quando a coesão interna de um grupo étnico está em crise; e podem existir etnicidades sem comunidades e até sem territórios, e comunidades potencialmente étnicas que lançam mão da etnicidade só esporadicamente. E o processo de midiatização do mundo faz aumentar as oportunidades de surgimento e crescimento de etnicidades simbólicas, desterritorializadas, intermitentes e associadas a outras, igualmente mobilizadoras, identidades sociais - por exemplo, ser jovem (ver, entre muitos, Gans, 1979; Eriksen, 1997; Jenkins, 1997; Appadurai, 1997; Castells, 1997). Nesse sentido, pode-se sugerir duas coisas: a) a cacofonia étnica - que segundo alguns pertenceria à América Latina e que tem contribuído para fazer desta região uma terra problemática para os paladinos das políticas identitárias de cunho étnico - é, na realidade, muito mais universal do que se pensa; $b$ ) é preciso rever as teorias que postulam a universalidade do sentimento étnico, pelo qual todo grupo social teria um quantum de etnicidade a ser expresso, já que, muitas vezes, essas teorias são sobretudo extrapolações da situação norte-americana para o resto do mundo (Poutignat e Streiff-Fenart, 1997:21-32). A identidade negra, ou negritude, dessa perspectiva, deixa de ser algo "natural" ou imanente nas relações entre "brancos" e "negros", para ser vista como um processo discursivo (Fry, no prelo) - o resultado de contingências e vicissitudes que a levam a surgir, em alguns momentos, assim como a diminuir de intensidade ou até sumir, em outros.

Em suma, acho necessário historicizar as práticas multiculturais e o multiculturalismo - insisto nessa diferença - pesquisando-os em sua própria contingência, não generalizando e evitando colocá-los simbolicamente sempre e somente no contexto norte-americano, que nos domina em muitos aspectos. É útil olhar também para o contexto europeu, porque variado e palco de debate entre noções de cidadania di- 


\section{Livio Sansone}

ferentes. Ademais, parecem-me pouco saudáveis generalizações internacionais sobre o multiculturalismo, referindo-se somente à literatura sobre países de fala inglesa ou que já foram colônias britânicas. Nesse sentido, é interessante um debate sobre as novas formas de cidadania e políticas que visam o respeito à diferença etnocultural que estão sendo experimentadas, com resultados variados, em países da América Latina, como Nicarágua, Bolívia e Colômbia ${ }^{10}$. Inclusive porque o contexto dessa região se distingue por ter (novas) demandas setoriais e particularistas, dentro de uma situação em que direitos universais (básicos) nunca chegaram a ser garantidos para a maioria.

Minha oposição não é, a princípio, às idéias que vêm de fora, porque todas as idéias acerca das noções de diversidade e diferença encontravam-se fora de lugar ou chegaram de fora em algum momento do seu percurso. Trata-se, mais do que tudo, de uma insatisfação com a pouca metodologia e sistemática da perspectiva comparativa que deveria estar na base da análise de sistemas de relações raciais e/ou interétnicas de países ou regiões diferentes. Haveria que se levar mais em conta que cada um desses sistemas reflete algum gênero de "localismo" ou até de idiossincrasia, mesmo quando seus símbolos viajam pelas ondas da globalização.

(Recebido para publicação em abril de 2003)

(Versão definitiva em setembro de 2003)

\section{NOTAS}

1. Reconheço, porém, que a situação de países que já foram colônias e que estão tentando se tornar sociedades plurais, em vez de multiculturais, como a Índia, a Malásia e a África do Sul, é também muito interessante (ver, a respeito, Rockefeller Foundation, 1984).

2. Trata-se de países onde o Instituto de Estudos das Migrações e Etnicidades de Amsterdã, do qual eu fui pesquisador, vem realizando uma grande pesquisa comparativa financiada pelo Conselho da Europa e, depois, pela União Européia (Vermeulen, 1997).

3. Formas incipientes de subsídios eram conhecidas também em sociedades antigas, como no Império Romano, com os pretorianos, e no Império Otomano, com os janízaros, mas tratava-se de grupos de inativos cuja função era formar um grupo de 
consenso, e de proteção, em torno do palácio imperial, mais do que de grupos de desempregados no sentido moderno do termo. Segundo Swaan (1988), o primeiro subsídio de desemprego de cunho moderno foi instituído na Alemanha por expressa vontade de um governo conservador e contra a opinião dos sindicatos.

4. Ver meu comentário ao relatório de Perez de Cuellar para as Nações Unidas intitulado "Our Creative Diversity" na homepage http://kvc.minbuza.nl/uk/archive/commentary/sansone.html.

5. Os Bálcãs mostram algumas versões de direita; a região dos Grandes Lagos, na África, também. O que aconteceu na ex-Iugoslávia contribuiu bastante para minha mudança. Minha primeira conferência internacional como antropólogo foi em 1984 em Dubrovnik, na antiga Iugoslávia, hoje Croácia. Publiquei o texto da palestra em uma revista, Migracja Tema, editada em Zagreb, que não existe mais.

6. Penso que uma guerra a favor da tolerância seria mais proveitosa que uma guerra a favor do multiculturalismo.

7. Sobre os avanços do debate e as limitações da proposta deste artigo, ver o número especial da revista Estudos Afro-Asiáticos (vol. 24, no 1, 2002) dedicado ao tema da pesquisa sobre relações raciais no Brasil, as prioridades e as agendas das fundações estrangeiras.

8. Hoje, estes são termos muito usados, na maioria dos casos, em um arcabouço inspirado pelo pós-modernismo. A estes dois autores, porém, deve ser creditada a primeira utilização sistemática, em linguagem acadêmica, dos termos hibridez e transculturalismo. Não estou ciente de alguma referência a esse mérito nos autores contemporâneos que mais usam tais termos. Felizmente, Bronislaw Malinowski (1947), na sua introdução à tradução inglesa do livro de Fernando Ortiz, Contrapunto Cubano del Tabaco y del Azucar, age de forma diferente, reconhecendo os méritos do autor nesse sentido.

9. Em um artigo recente, Sidney Mintz (1998) critica de forma brilhante o uso descontextualizado e a-histórico, por parte de muitos cientistas sociais que se definem como pós-modernistas, de termos como crioulização, transnacionalismo e até globalização.

10. Países cujas Constituições têm sido recentemente modificadas, incorporando itens que definem o país como sendo multiétnico e multicultural.

\section{REFERÊNCIAS BIBLIOGRÁFICAS}

ALEXANDER, Claire. (1996), The Art of Being Black. Oxford, Clarendon Press.

APPADURAI, Arjun. (1997), Modernity at Large. Minneapolis, University of Minnesota Press.

BACK, Les. (1996), New Ethnicities and Urban Culture. London, UCL Press. 


\section{Livio Sansone}

BOURDIEU, Pierre e WACQUANT, Loïc. (1998), “Sobre as Artimanhas da Razão Imperialista”, in M. A. Nogueira e A. Catani (orgs.), Escritos de Educação. Petrópolis, RJ, Vozes, pp. 17-32.

CASTELLS, Manuel. (1997), The Power of Identity. Oxford, Blackwell.

CASTLES, Stephen e MILLER, Mark J. (1993), The Age of Migration. International Population Movements in the Modern World. Basingstoke, Macmillan.

DIOUF, Mamadou. (1999), "The French Colonial Policy of Assimilation and the Civility of the Originaires of the Four Communes (Senegal): A Nineteenth Century Globalization Project", in B. Meyer e P. Geschiere (eds.), Globalization and Identity. Dialectics of Flow and Closure. Oxford, Blackwell, pp. 71-96.

ERIKSEN, Thomas H. (1997), "Mauritian Society between the Ethnic and the Non-ethnic", in H. Vermeulen e C. Govers (eds.), The Politics of Ethnic Consciousness, London/New York, Macmillan/St. Martin's Press, pp. 250-276.

FRY, Peter. (2000), "Politics, Nationality and the Meaning of 'Race' in Brazil”. Daedalus, vol. 129, no 2 (special issue "Brazil. Burden of the Past. Promise of the Future"), pp. 83-118.

. (no prelo), “As Aparências que Enganam: Reflexões sobre ‘Raça' e Saúde no Brasil”, , in S. Maio e L. Sansone (orgs.), Raça/Etnicidade na América Latina. Questões sobre Saúde e Direitos Reprodutivos. Rio de Janeiro, Fiocruz.

GANS, Herbert. (1979), "Symbolic Ethnicity: The Future of Ethnic Groups and Culture in America". Ethnic and Racial Studies, vol. 1, no 2, pp. 1-20.

GROSFOGUEL, Ramon. (1997), “Colonial Caribbean Migrations to France, the Netherlands, Great Britain and the United States". Ethnic and Racial Studies, vol. XX, no 3, pp. 594-612.

HANDLER, Richard. (1988), Nationalism and the Politics of Culture in Quebec. Madison, The University of Wisconsin Press.

HEWITT, Roger. (1984), White Talk, Black Talk. Interracial Friendship and Communication among Adolescents. London, Cambridge University Press.

JENKINS, Richard. (1997), Rethinking Ethnicity. London, Sage.

LUCASSEN, Jan e PENNINX, Rinus. (1994), Nieuwkomers Nakomelingen. Immigraten in Nederland 1550-1993. Amsterdam, Het Spinhuis.

MALINOWSKI, Bronislaw. (1947), "Introduction", in F. Ortiz, Cuban Counterpoint. Tobacco and Sugar. London, Duke University Press, pp. lvii-lxiv.

MINTZ, Sidney. (1998), “The Localization of Anthropological Practice. From Area Studies to Transnationalism". Critique of Anthropology, vol. 18, n 2, pp. 117-133.

NEDERVEEN PIETERSE, Jan. (2001), “Hybridity, so What? The Anti-Hybridity Backlash and the Riddles of Recognition". Theory, Culture and Society, vol. 18, no 2-3, pp. 219-246.

ORTIZ, Fernando. (1947), Cuban Counterpoint. Tobacco and Sugar (introdução de Bronislaw Malinowski). New York, Knopf. 
PARSONS, Talcott. (1968), "The Problem of Polarization on the Axis of Color", in J. H. Franklin (ed.), On Color and Race. Boston, Houghton Mifflin Company, pp. 349-369.

PIERUCCI, Antonio Flávio. (1999), Ciladas da Diferença. São Paulo, Editora 34.

POUTIGNAT, Philippe e STREIFF-FENART, Jocelyne. (1997), Teorias da Etnicidade. São Paulo, Ed. UNESP.

QUIJANO, Aníbal. (1989), "The Paradoxes of Modernity in Latin America”. International Journal of Politics, Culture and Society, vol. 3, no 2, pp. 147-177.

REGT, Ali de. (1978), Arbeidersgezinnen en beschavingsarbeid: ontwikkelingen in Nederland 1870-1940. Amsterdam, Boom.

ROCKEFELLER FOUNDATION. (1984), International Perspective on Affirmative Action. Conference Report.

SANSONE, Livio. (1998), “Racismo sem Etnicidade. Políticas Públicas e Discriminação Racial em Perspectiva Comparada". Dados, vol. 41, no 4, pp. 751-784.

. (1999), "Small Places, Large Migrations. Notes on the Specificity of the Population of Surinamese and Antillean Origin in the Netherlands". Review, vol. XXII, no 4 .

_. (no prelo), “Perspectivas sobre 'Raça' e Etnicidade dentro da Pesquisa Aplicada e da Intervenção no Campo da Saúde Reprodutiva: O Caso Afro-Latino-Americano", in S. Maio e L. Sansone (orgs.), Raça/Etnicidade na América Latina. Questões sobre Saúde e Direitos Reprodutivos. Rio de Janeiro, Fiocruz.

STEINBERG, Richard. (1988), The Ethnic Myth. Race, Ethnicity and Class in America. New York, Atheneum.

SWAAN, Abraham de. (1988), Zorg en de Staat. Amsterdam, Bert Bakker.

TAYLOR, Charles. (1994), "The Politics of Recognition", in A. Gutmann (ed.), Multiculturalism. Princeton, NJ, Princeton University Press, pp. 25-74.

VERMEULEN, Hans (ed.). (1997), Immigrant Policy for a Multicultural Society. Bruxelles, Migration Policy Group. . (2001), Imigração, Integração e a Dimensão Política da Cultura. Lisboa, Colibri.

WACQUANT, Loïc. (1998), “L'Emprisonnement des 'Classes Dangereuses' aux États-Unis", Le Monde Diplomatique, julho, pp. 20-21.

WORLD COMMISSION ON CULTURE AND DEVELOPMENT. (1995), Report: Our Creative Diversity. Paris, UNESCO.

WULFF, Helena. (1988), "Twenty Girls. Growing up, Ethnicity and Excitement in a South London Microculture". Stockholm, Stockholm Studies in Social Anthropology, no 21 . 


\section{Livio Sansone}

\section{ABSTRACT \\ Multiculturalism, State, and Modernity: Nuances in Some European Countries and the Debate in Brazil}

This paper, based on ethnographic research, presents the most evident changes among groups of low-income youth, the vast majority of whom are black or mixed-race, in Salvador and Rio de Janeiro, Brazil, over the course of ten years. The notions of ideal work and ideal male or female partner change along with the growing popularity of a perception of citizenship that is increasingly centered on individuals and their freedom of movement and conspicuous consumption - the measurement of participation in societies and their collective rituals. Among these youth there is also a renewed interest in blackness and youth, features which are no longer hidden, but celebrated and vindicated. In this context, new demands for citizenship take shape, along with a new feeling of relative dispossession: both are indicators of the new face of poverty in Brazil.

Key words: multiculturalism; citizenship; youth; Salvador; Rio de Janeiro

\section{RÉSUMÉ \\ Multiculturalisme, État et Modernité: Nuances dans quelques Pays Européens et Discussion au Brésil}

Dans cet article, résultat d'une recherche ethnographique, on montre les changements les plus significatifs observés, au long d'une décennie, parmi des groupes de jeunes défavorisés, Noirs et métis pour la plupart, à Salvador de Bahia et à Rio de Janeiro. La notion de travail idéal ainsi que celle de partenaire idéal changent au fur et à mesure que devient populaire une certaine perception de la citoyenneté de plus en plus centrée sur l'individu et sa liberté d'action et sur la consommation à outrance - la mesure de la participation de chacun dans la société et dans ses rituels collectifs. Chez cette jeunesse, on observe aussi un renouveau de l'intérêt pour la négritude et la condition de jeune, facteurs qui actuellement ne sont plus cachés mais, au contraire, célébrés et revendiqués. Dans ce cadre, de nouvelles demandes de citoyenneté prennent forme ainsi qu'un nouveau sentiment de privation relative; ceux-ci deviennent des indicateurs du visage actuel de la pauvreté au Brésil.

Mots-clé: multiculturalisme; citoyenneté; jeunes; Salvador; Rio de Janeiro 